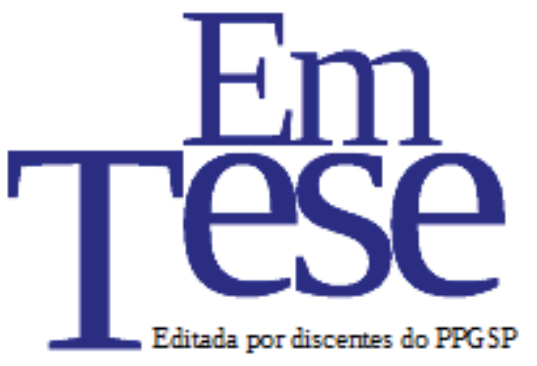

UFSC

PPG SP PROG RAMA DE

POS-GRADUAÇÃO EM

Sociologia Política

\title{
Efeito contextual de "amigos e vizinhos" nas eleições presidenciais brasileiras: $o$ caso da votação do candidato Aécio Neves no estado de Minas Gerais
}

\author{
Aleksei Zolnerkevic ${ }^{1}$ \\ Hilton Cesario Fernandes ${ }^{2}$
}

Resumo: O artigo avalia a influência do efeito contextual conhecido na literatura como "efeito de amigos e vizinhos" na votação do candidato Aécio Neves na eleição presidencial de 2014. Aplicando a fórmula da vantagem do estado natal introduzida por Lewis-Beck e Rice (1983), foi elaborado um banco de dados com os três primeiros colocados nas eleições presidenciais brasileiras de 1989 a 2014. Os dados mostram que a vantagem do estado natal nas eleições presidenciais foi maior entre os candidatos com menor estrutura partidária e nos estados menos populosos. Por outro lado, no caso do candidato Aécio Neves, embora a vantagem do estado natal tenha sido significativa não foi suficiente para compensar efeitos concorrentes mais importantes que atuaram no território.

Palavras-chave: Comportamento eleitoral. Efeito de amigos e vizinhos. Eleições presidenciais.

\section{"Friends and neighbours contextual effect" in brazilian presidential elections: the} Aécio Neves voting case in Minas Gerais

\begin{abstract}
In this article, we evaluated the influence of a contextual effect known as "Friends and neighbours effect" on Aécio Neves's voting performance in the 2014 Brazilian presidential election. Using "hometown advantage" formula introduced by Lewis-Beck e Rice (1983), we built a database for the top three candidates in the 1989 to 2014 Brazilian presidential elections. We found that "hometown advantage" was higher between the candidates with lower party structure and in less populated states. On the other hand, although Aécio Neves had a significant "hometown advantage", it was not enough to compensate other most important effects acting at the same time in the territory.
\end{abstract}

Keywords: Electoral behavior. Friends and neighbours effect. Brazilian presidential elections

\footnotetext{
${ }^{1}$ Mestre e Doutorando em Geografia Humana pela FFLCH - USP. E-mail: alekseizolner@gmail.com.

${ }^{2}$ Mestre em Ciência Política - USP. Professor da Fundação Escola de Sociologia e Política de São Paulo

-FESPSP. E-mail: hiltoncesario@gmail.com.
} 


\section{Introdução}

Na eleição presidencial de 2014, o candidato pelo Partido da Social Democracia Brasileira (PSDB), Aécio Neves, não conseguiu liderar a votação em seu estado natal, Minas Gerais, sendo superado pela candidata Dilma Rousseff, do Partido dos Trabalhadores (PT), por uma diferença de 412.991 (3,7\%) votos no primeiro turno da eleição e por 548.697 (4,8\%) votos no segundo turno.

A decisão dos eleitores no estado mineiro foi amplamente discutida por analistas na imprensa e em debates sobre o resultado da eleição, com conclusões diversas, deixando em aberto se de fato uma votação mais expressiva de Aécio em seu estado poderia ser suficiente para mudar o saldo final da eleição.

Após o primeiro turno, a campanha petista aproveitou o fato para apontar a derrota de Aécio como uma indicação de má avaliação do ex-governador. Propagandas negativas foram divulgadas junto com a frase "quem conhece Aécio, não vota em Aécio", de modo a vincular o resultado da votação do candidato em Minas Gerais à avaliação de seu governo e de seu sucessor do PSDB (Antônio Anastasia).

O objetivo deste artigo é analisar o desempenho de Aécio Neves em Minas Gerais nas eleições presidenciais de 2014 a partir da discussão de uma literatura pouco explorada no Brasil, sobre a tese contextual no comportamento eleitoral e a hipótese do efeito contextual de "amigos e vizinhos" apresentada primeiramente no estudo clássico de Vladimir O. Key (1949).

\section{Conceitos gerais}

O conceito de "contexto" é visto de forma geral na sociologia política como o ambiente externo mais próximo ao eleitor, que circunscreve e limita as interações e informações sociais a que o eleitor tem acesso nas suas diversas escalas: local de moradia, bairro, distrito, cidade, estado etc. (HUCKFELDT e SPRAGUE, 1987; HUCKFELDT, et al, 2004).

Alguns autores também associam a ideia de contexto, principalmente na geografia, à noção de pertencimento a uma estrutura social. O contexto, nessa perspectiva, é visto como o conjunto de elementos que compõem o "lugar" onde as 
pessoas vivem: as características físicas, sociais, históricas e econômicas, além dos processos econômicos e sociais ali associados. A geógrafa britânica Dorren Massey (1994), por exemplo, define contexto como "um agrupamento de redes (...) vinculados adicionalmente ao lugar físico" "3. A partir da ideia de que as pessoas tomam suas decisões usando como parâmetro o lugar onde elas foram socializadas, o contexto não seria visto apenas como um ambiente neutro, um invólucro das interações sociais e das informações a quem os indivíduos têm acesso, mas sim um agente central na formação do comportamento e das ações humanas (ver AGNEW, 1987).

A tese contextual sempre esteve presente nos estudos do comportamento eleitoral. Nos primeiros estudos da escola de Columbia, por exemplo, Lazarsfeld et al (1944) já destacava a importância do ambiente e contexto social dos indivíduos nas suas escolhas eleitorais. Para ele, as interações sociais interpessoais dos eleitores com os seus contatos mais próximos dentro de uma rede social (família, amigos, colegas de trabalho) reforçariam as próprias posições políticas e eleitorais, baseadas nas suas predisposições sociológicas, criando assim um espaço de consenso eleitoral em determinados contextos.

Dessa forma, a tese contextual ou abordagem contextual do comportamento eleitoral defende que os eleitores, além de influenciados pelas suas predisposições sociológicas e suas características composicionais (classe social, escolaridade etc.), também são influenciados pelo contexto social à sua volta.

Os primeiros efeitos contextuais identificados pela literatura foram: o "efeito de vizinhança", identificado na Suécia em 1937, por Herbert Tingsten, que percebeu que as pessoas da classe trabalhadora daquele país tendiam a votar para partidos de esquerda quando moravam em bairros trabalhadores; o "efeito de amigos e vizinhos", de Key (1949), que será tratado nesse artigo; e o efeito de "breakage" identificado nos primeiros estudos da escola de Columbia, na década de 1950. Berelson (1954) refere-se a esse último como a tendência de eleitores com uma visão minoritária em certo contexto acabarem adotando a opinião da maioria como reflexo do ambiente político local (ver WOOLSTENCROFT, 1980).

Durante a revolução quantitativa da geografia anglo-saxônica, diversos geógrafos como Cox (1969) e Reynolds (1969) desenvolveram teorias que explicavam

\footnotetext{
3 “(...) place or context may be defined by group membership or network ties in addition to physical location" (MASSEY, 1994).
} 
esses efeitos contextuais a partir de modelos de difusão e contágio espacial. Essas teorias enfatizavam a propriedade da "propinquindade", ou distância espacial entre as pessoas. Kevin Cox argumenta, por exemplo, que as pessoas pertencem a redes sociais de informação através dos contatos e interações sociais. As pessoas dentro dessas redes sociais representam elos ou "nós" (nodes), através de três papeis distintos: receber, enviar e processar informações. Também podem representar "conectores" (links), ligando duas ou mais redes. A hipótese central desses estudos é a de que pessoas próximas geograficamente (distância espacial) tendem a pertencer às mesmas redes sociais.

Estudos posteriores tanto na sociologia política (HUCKFELDT e SPRAGUE 1987; HUCKFELDT et al, 2004) bem como na geografia contemporânea (RON JOHNSTON, 1986, 2005) argumentam que pessoas próximas umas às outras não pertencem necessariamente à mesma rede social de informação. Um modelo alternativo à "propinquidade" é a do contato social via conversação, apresentado primeiramente por Miller (1977 apud MACALLISTER et al, 2001). Nos termos desse autor, "pessoas que conversam juntas votam juntas" 4 .

Segundo Huckfeldt e Sprague (1987), as pessoas escolhem preferencialmente interagir socialmente com pessoas de opiniões políticas parecidas às suas, procurando evitar opiniões dissonantes, formando-se assim redes sociais de informação homogêneas. A forma como as pessoas escolhem com quem vão interagir socialmente, interpretando e reavaliando suas próprias opiniões em consequência dessa interação, é reproduzida pelo indivíduo quando este interage com outras formas de informação política: formadores de opinião, mídias de massa e campanhas eleitorais. Essa ideia vai ao encontro do pensamento Downsiano de que o homem racional, para reduzir os custos na obtenção de informações políticas, busca obtê-las de fontes que compartilham dos seus próprios pontos de vista, pessoas próximas, formadores de opinião nas suas comunidades locais ou através de mídias de massa alinhadas com suas posições (DOWNS, 1999).

Nos dias de hoje, no entanto, dificilmente as pessoas conseguem se manter isoladas socialmente em grupos politicamente homogêneos e não serem expostas a opiniões discordantes das suas (HUCKFELDT et al, 2004), gerando o que Lazarsfeld

\footnotetext{
${ }^{4}$ People who talk together vote together (MACALLISTER et al, 2001, p. 42).
} 
(1944) chama de "pressões cruzadas": o eleitor invariavelmente toma conhecimento de posições políticas apontando a diversas direções.

Nesse sentido, o contexto social do eleitor, as mídias de massa e as campanhas políticas exerceriam um papel cada vez mais importante na decisão do voto ao apresentarem informações políticas relevantes ao eleitor, tanto para reforçar suas predisposições políticas pré-existentes, quanto para mudar sua posição.

\section{Efeito de "amigos e vizinhos"}

No estudo "Southern politics in state and nation", de 1949, o cientista político V. O. Key analisou as eleições intrapartidárias americanas, mais especificamente as eleições primárias democratas no estado do Alabama em 1946. Key notou que os candidatos concorrentes apresentaram os melhores desempenhos nos condados em que residiam e nos circunvizinhos. Segundo o autor, a eleição foi decidida nos seguintes termos: enquanto o candidato perdedor obteve a maior parte dos votos concentrada no entorno do seu condado de residência, o vencedor por sua vez não apenas conquistou votos da mesma forma, como também ao redor da região onde passou a infância (boyhood) (TAYLOR e JOHNSTON, 1979).

Esse excessivo "localismo" em que as decisões de voto são grandemente influenciadas pela localização relativa dos eleitores aos candidatos, ao qual Key chamou de "efeito de amigos e vizinhos", seria consequência da falta de diferenças reconhecíveis entre os candidatos, assim como o pouco interesse dos eleitores pelos temas de relevância pública em pauta naquela eleição específica.

$\mathrm{Na}$ escassa literatura sobre esse efeito (ver JOHNSTON et al, 2016), temos duas explicações principais: a primeira é que o efeito de "amigos e vizinhos" ocorreria porque os eleitores da região em que o candidato reside simplesmente têm maior conhecimento sobre ele - sua pessoa, sua família, bem como sua trajetória na vida pública. Quanto mais contatos ou nós (nodes) em redes de informação o candidato tem, mais fácil é a difusão espacial da sua mensagem pelo contexto. Em outras palavras, os apoios eleitorais dos candidatos dependem de como se dá a distribuição das informações relevantes sobre eles nos distritos eleitorais, seja através das redes de contatos locais ou pela mídia de massa. 
Em distritos eleitorais maiores, territorialmente ou em população, a difusão das informações sobre os candidatos se resume àquelas informações trazidas pelas redes de comunicação de massa. Estudando as eleições estaduais da Califórnia, Bowler et al (1993) observou que, como as mídias locais usadas pelos candidatos para difundir suas mensagens não cobriam o estado de uma forma uniforme, havia uma distribuição desigual das informações sobre eles, gerando um efeito de "amigos e vizinhos". Ou seja, os candidatos foram mais bem votados próximos a seus condados de origem, onde suas mensagens eram melhor difundidas.

Os candidatos incumbentes numa eleição majoritária, nesse sentido, teriam uma vantagem sobre os candidatos desafiantes, por serem mais conhecidos devido à natureza do cargo que ocupam. Os candidatos incumbentes devido a esse maior conhecimento entre os eleitores seriam menos dependentes do efeito de "vizinhos e amigos" (RICE e MACHT, 1987a), o mesmo acontecendo com candidatos que têm à sua disposição uma ampla estrutura partidária e recursos financeiros para ampliar sua campanha para além da sua região.

A segunda explicação defende que o eleitor local tende a escolher o candidato da sua região acreditando que este irá promover os interesses locais da comunidade. Analisando os resultados das eleições para governador nos EUA do ano de 1982, ao constatar a existência do efeito de "amigos e vizinhos", Rice e Macht (1987b) argumentam que os candidatos locais teriam um maior poder mobilizador sobre os eleitores da sua região. Eles encontram evidências de que pessoas que geralmente se abstém de votar, ou então são leais ao partido do candidato adversário, acabam decidindo por escolher o candidato local acreditando que ele possa fazer mais pela sua comunidade. Essa ideia de que o eleitor vota em candidatos locais acreditando em possíveis benefícios para si ou para sua região pode ser traduzida no conceito de conexão eleitoral, muito utilizado na ciência política brasileira.

A conexão eleitoral seria a relação condicional que o político tem entre sua atividade parlamentar (no caso de cargos legislativos) e a arena eleitoral (PEREIRA e MUELLER, 2003). Segundo Monteiro (2010), o pressuposto da conexão eleitoral é a de que os eleitores elegem ou reconduzem um político a um cargo público caso aprovem a sua atuação política ou vida pública pregressa. Nesse sentido, os políticos buscariam, 
durante seus mandatos, trabalhar a favor do seu reduto eleitoral com o objetivo de garantir a reeleição.

Uma série de estudos aponta a conexão eleitoral como a principal preocupação dos políticos durante a sua vida parlamentar (AMES, 1995, 2003; PEREIRA e RENNÓ 2001). Durante os seus mandatos, os congressistas procurariam ao máximo favorecer suas respectivas bases territoriais de apoio eleitoral, criando distritos eleitorais "informais".

Estudos mais recentes (AVELINO et al 2011, 2012; SILVA 2013) argumentam que a concentração espacial de votos, através desses mecanismos de conexão eleitoral, seria apenas mais uma estratégia eleitoral disponível ao candidato. Segundo os dados apresentados por Avelino et al (2011), os candidatos eleitos geralmente têm um nível de concentração menor do que os não eleitos, concluindo que essa estratégia não seria a mais eficaz. O candidato em começo de carreira apresentaria padrões de votação concentrados municipalmente e, com o passar do tempo, essa concentração passaria para uma escala regional, para finalmente apresentar um padrão de votação disperso no distrito eleitoral inteiro.

A contribuição da literatura sobre o efeito de "amigos e vizinhos" para esses estudos sobre conexão eleitoral e existência de distritos informais, interpretando a hipótese lançada por Avelino (2011), é a de que, para aqueles candidatos em início de carreira ou sem o apoio de uma estrutura partidária e de campanha, o "localismo" e a consequente concentração espacial de votos talvez não seja uma estratégia eleitoral intencional, mais sim uma condição inerente ao candidato desconhecido. Aqueles candidatos que perpetuariam um padrão de votação concentrado a partir de uma conexão eleitoral seriam uma minoria que se beneficiariam de situações circunstanciais, por exemplo, de municípios concentrados dominantes, como no postulado de Ames (2003, 2012). Apenas quando o candidato começa a ficar mais conhecido e ganha acesso aos recursos do partido, tais como estrutura física e financeira, subindo na hierarquia partidária, é que ele consegue expandir sua influência regionalmente e ser melhor conhecido no distrito eleitoral, passando assim a apresentar um padrão espacial de votação mais disperso. 


\section{Efeito de "amigos e vizinhos" nas eleições presidenciais}

Estudos eleitorais na literatura norte-americana (LEWIS-BECK e RICE 1983; DISARRO et al, 2007) indicam que, na maioria das vezes, os candidatos à presidência nos EUA se beneficiam do efeito de "amigos e vizinhos" e que os dois grandes partidos do país estão conscientes dessa vantagem. Assim, observa-se que de 1884 até 1980, $54 \%$ dos candidatos presidenciais vieram dos seis estados mais populosos (como a eleição presidencial americana é indireta, os partidos procuram nomear candidatos dos estados mais populosos e, portanto, com um maior número de delegados).

Lewis-Beck e Rice (1983) apresentam uma fórmula para calcular o que denominam de vantagem eleitoral do estado natal ${ }^{5}$. De acordo com a fórmula, essa vantagem seria definida pelo desvio da porcentagem de votos atual no estado natal em relação à porcentagem de votos esperada naquele estado, sendo esse desvio ajustado pela popularidade eleitoral nacional do candidato:

$H=\left(S_{a}-S_{e}\right)-\left(N_{a}-N_{e}\right)$

Onde $H$ é a vantagem eleitoral do estado natal, $S_{a}$ é a porcentagem atual de votos do candidato no seu estado natal, $S_{e}$ é a média da porcentagem de votos do seu partido nas cinco últimas eleições presidenciais naquele estado, $N_{a}$ é a porcentagem de votos atual do candidato no país e $N_{e}$ é a média da porcentagem de votos do partido no país nas últimas cinco eleições presidenciais.

Analisando essa vantagem nas eleições americanas entre 1880 e 1980, o autor observou que a vantagem do estado natal foi positiva na maioria das vezes e que não houve decréscimos com o passar do tempo.

Uma constatação importante encontrada foi que a vantagem do estado natal é mais significativa nos estados com menor população. A explicação para essa constatação é que em estados menos populosos haveria uma maior propensão do eleitor a decidir o seu voto com base no localismo. "Os cidadãos desses estados têm uma maior probabilidade de conhecer melhor o candidato local, seus amigos, até o candidato em pessoa"6 (LEWIS-BECK e RICE, 1983). Isto acarreta em um dilema para os estrategistas partidários quando nomeiam o seu candidato vindo de um estado pequeno

\footnotetext{
5 "Home state advantage".

${ }^{6}$ The citizens of these states are more likely to know the candidate's home town, his friends, even the candidate himself (LEWIS-BECK e RICE, 1983, p. 552).
} 
ou grande em população: geralmente a opção é pelo estado mais populoso em que a menor vantagem do estado natal (em porcentagem) é compensada pelo maior número de eleitores.

\section{Vantagem do estado natal nas eleições presidenciais brasileiras}

Como visto, na literatura americana a partir de Key (1949) a tendência de o candidato ter um desempenho eleitoral satisfatório na sua região natal ou residencial e circunvizinha é conhecida como o efeito contextual denominado de "amigos e vizinhos", que é identificado tanto em eleições regionais e primárias intrapartidárias (RICE e MACHT 1987a, 1987b; BOWLER et al, 1993) como em eleições presidenciais (LEWIS-BECK e RICE,1983; DISARRO et al, 2007).

É de se esperar, portanto, que candidatos à presidência do Brasil consigam votações melhores em seus estados de origem em relação a outras regiões, seja porque são mais conhecidos ou por uma atuação mais próxima da população. Não é por acaso que jornalistas e campanhas adversárias questionam a real capacidade de liderança dos candidatos que não alcançam a vitória entre os eleitores de sua base eleitoral.

Utilizando a fórmula apresentada em Lewis-Beck e Rice (1983), calculamos a vantagem eleitoral do estado natal para os três primeiros colocados em cada umas das eleições presidenciais de 1989 a 2014, totalizando 23 casos. Em seguida, analisamos o impacto conjunto de algumas variáveis sobre essa vantagem do estado natal, por meio de uma análise de regressão linear simples.

Consideramos para o levantamento o estado de origem e/ou aquele onde o candidato desenvolveu sua carreira política. Por exemplo, para o candidato terceiro colocado em 1989, Leonel Brizola, do PDT, consideramos como seus estados natais tanto o Rio de janeiro, quanto o Rio Grande do Sul, pelo fato do candidato ter sido governador de ambos e originário desse último. Já o candidato Luís Inácio Lula da Silva, do PT, apesar de ter nascido em Pernambuco, construiu sua carreira política em São Paulo, assim como sua correligionária, Dilma Rousseff, originária de Minas Gerais, se estabeleceu politicamente no Rio Grande do Sul. Nesses últimos dois casos, consideramos São Paulo e Rio Grande do Sul, respectivamente, como os seus estados de origem. Por fim, na eleição de 2014, no caso de Marina Silva, consideramos além do 
estado do Acre também o estado de Pernambuco como estado de origem, por ser o estado natal do seu companheiro de chapa, Eduardo Campos.

Tanto a média da porcentagem de votos das eleições anteriores do estado de origem, $S_{e}$, quanto nacional, $N_{e}$, foram calculadas a partir das médias das porcentagens das eleições anteriores até o limite de 3 eleições ${ }^{7}$. Os resultados da análise (Tabela 1) mostram uma correlação negativa forte entre a vantagem eleitoral do estado natal $\mathrm{H}$ e as duas primeiras variáveis: a do candidato pertencer aos partidos PT ou PSDB e ser originário de estados com mais população.

Tabela 1 - Regressão Linear simples entre a vantagem eleitoral do estado natal $(\mathrm{H})$ obtida pelos três primeiros candidatos das eleições presidenciais de 1989 a 2014 e algumas variáveis independentes $(\mathrm{N}=23)$.

\begin{tabular}{llll}
\hline Variáveis Independentes & $\mathrm{R}^{2}$ & Coeficiente & $\mathrm{p}$-valor \\
\hline PT, PSDB/Outros $(0,1)$ & 0,551 & $-0,742$ & 0,000 \\
Tamanho da População & 0,434 & $-0,658$ & 0.001 \\
Colocação $(1,2,3)$ & 0,270 & 0,519 & 0,011 \\
Incumbente $(0,1)$ & 0,226 & $-0,476$ & 0,022 \\
Período (ano eleitoral) $(1,2,3,4 \ldots)$ & 0,046 & $-0,215$ & 0,325 \\
\hline
\end{tabular}

Caso o candidato concorra pelos dois grandes partidos, PT e PSDB (variável dummy 0,1), a vantagem do estado natal é menor. Esse resultado faz sentido quando pensamos que ambos, PT e PSDB, junto com o PMDB, são os maiores e mais bem estruturados partidos brasileiros tanto territorialmente como em relação à exposição e o tempo de televisão durante as campanhas eleitorais. Nesse sentido, a desproporção das informações sobre os candidatos territorialmente é minimizada. Os candidatos dos outros partidos, devido à menor exposição na mídia, dependem mais das redes políticas construídas pelo candidato no seu estado natal ou onde ele exerceu sua vida política buscando o efeito de "amigos e vizinhos". Partidos menores também geralmente são mais bem consolidados em certos estados do que em outros. Isso se reflete no desempenho de seus candidatos, como é o caso, por exemplo, no desempenho relativamente expressivo de Heloísa Helena em 2006, no Rio de Janeiro, onde seu partido, o PSOL, está mais bem estruturado.

\footnotetext{
${ }^{7}$ Ciro Gomes, por exemplo, lançou-se candidato em apenas duas oportunidades no período de 1989 a 2014 e só em 1998 figurou entre os três primeiros candidatos.
} 
Quanto maior a população do estado natal do candidato, menor a vantagem obtida por ele. Como vimos, segundo Lewis-Beck e Rice (1983), analisando o caso americano, esse fenômeno ocorre porque os eleitores dos estados com menor população teriam uma maior tendência a decidir o seu voto baseado em pensamentos localistas, ou seja, apoiar o seu "home town boy" pelo simples motivo do candidato ser originário daquele estado, ou por ser mais conhecido ali, ou por acreditarem que sua eleição trará mais benefícios para seu estado. Em estados mais desenvolvidos esse efeito seria menor.

Os dados mostram também que candidatos mais bem colocados ou concorrendo à reeleição são menos beneficiados pelo efeito de "amigos e vizinhos", novamente, por serem mais conhecidos. Embora estatisticamente pouco significante, a vantagem do estado natal diminui com o passar do tempo, talvez como consequência de um processo de nacionalização crescente das eleições presidenciais de 1989 para as mais recentes. Na eleição de 1989 houve um forte impacto desse efeito, pois não havia nenhum candidato de projeção nacional, a exceção de Ulisses Guimarães, do PMDB. Assim, essa eleição teve um forte caráter local, com os eleitores votando principalmente nos políticos de seus estados: Collor em Alagoas (34 pontos H), Covas $^{8}$ em São Paulo (11,2 pontos H) e Brizola no Rio Grande do Sul e no Rio de Janeiro (46,2 e 35,6 pontos H).

Podemos deduzir a partir desses dados, portanto, que candidatos de partidos com uma menor estrutura de campanha, sendo menos conhecidos nacionalmente e com menor acesso à mídia de massa, tendem a ser mais beneficiados pelo "efeito de amigos e vizinhos". Isso pode ser constatado nos desempenhos de Ciro Gomes em 1998 (23,3 pontos H) e em 2002, e no caso de Anthony Garotinho em 2002 (24,4 pontos H), ambos candidatos vitoriosos nos seus estados de origem nessas eleições. Mesmo não sendo vitoriosos, Cristovam Buarque (PDT) e Heloísa Helena (PSOL) em 2006, e Marina Silva (PV) em 2010 (23.4 pontos H), tiveram suas melhores votações em seus estados de origem ou naqueles onde seus partidos se apresentavam mais estruturados.

Onde o candidato é menos conhecido ele necessita ter acesso suficiente às mídias de massa (televisão e rádio, principalmente) e uma estrutura mínima partidária e de campanha, que geralmente são restritos aos três grandes partidos brasileiros, PT, PSDB e PMDB, que teoricamente, não dependem tanto do "efeito de amigos e

\footnotetext{
${ }^{8}$ Na eleição presidencial de 1989 o candidato do PSDB Mario Covas foi o quarto colocado com 11,55\% dos votos válidos.
} 
vizinhos", ao contrário do que ocorre com postulantes que contam com menor estrutura de campanha.

\section{Efeito de "amigos e vizinhos" e o caso de Aécio Neves na eleição presidencial de 2014}

Declarações do ex-governador mineiro Antônio Anastásia (PSDB) antes das eleições de 2014 mostraram uma grande expectativa de vitória em São Paulo e Minas Gerais:

São os dois Estados mais populosos, ambos governados pelo PSDB há muitos anos. Isso nos dá um cacife para ter uma grande vantagem. Em Minas, havendo um candidato mineiro, como não havia há muitos anos, temos condição de abrir grande frente ${ }^{9}$.

De fato, o candidato Aécio Neves obteve uma vitória expressiva no estado de São Paulo, que pode ser atribuída à forte estrutura de seu partido, que vem elegendo governadores nesse estado por várias eleições consecutivas. Por outro lado, embora tenha sido derrotado em Minas Gerais, o efeito de "amigos e vizinhos" foi positivo no estado como podemos verificar pelos dados estatísticos a seguir.

Calculamos a vantagem do estado natal $(H)$ obtida por Aécio Neves utilizando a fórmula apresentada por Lewis-Beck e Rice (1983):

$H=\left(S_{a}-S_{e}\right)-\left(N_{a}-N_{e}\right)$

Utilizamos os seguintes dados: a porcentagem de votos obtida pelo candidato Aécio Neves em Minas Gerais em 2014, $S_{a}=39,7 \%$; a média da porcentagem obtida pelo PSDB nas três últimas eleições presidenciais naquele estado (2002, 2006 e 2010), $S_{e}=31,4 \%$; a porcentagem de votos do candidato Aécio Neves no Brasil em 2014, $N_{a}=$ 33,5\%; e a média da porcentagem obtida pelo PSDB nas três últimas eleições presidenciais nacionalmente $N_{e}=32,4 \%$.

Obtivemos o seguinte resultado:

$$
\begin{aligned}
& H=(39,7-31,4)-(33,5-32,4) \\
& H=(8,3)-(1,1) \\
& H=7,2
\end{aligned}
$$

\footnotetext{
${ }^{9}$ Entrevista concedida à Revista Época, edição de 07 de abril de 2014.
} 
Os números mostram que o candidato Aécio Neves obteve um acréscimo de 7,2\% em relação aos desempenhos anteriores do seu partido no estado. Essa vantagem, no entanto, não foi suficiente para que ele vencesse no estado: Aécio Neves perdeu para Dilma Rousseff, do PT, em Minas Gerais por 43,5\% a 39,8\%.

Como vimos, a vantagem de votos obtida através do efeito de "amigos e vizinhos" no estado natal do candidato se comporta inversamente ao tamanho da população desse estado. Sendo Minas Gerais o segundo estado mais populoso do Brasil, atrás apenas de São Paulo, é de se esperar que o efeito de "amigos e vizinhos" não fosse tão excepcional como a sua campanha esperava. Como apresentado por Lewis-Beck e Rice (1983), seria um dilema para os líderes partidários entre se obter o máximo de vantagem a partir do efeito de amigos e vizinhos em um estado menos populoso contra escolher um candidato de um estado mais populoso compensando o menor efeito contextual esperado.

Depois de Mário Covas, em São Paulo, na eleição presidencial de 1989, na qual preponderou o fator local, Geraldo Alckmin obteve a melhor vantagem do estado natal $(H)$ do PSDB em 2006, com 8 pontos $H$ no estado mais populoso do Brasil. Isto seria um paradoxo para o efeito de "amigos e vizinhos" já que, segundo a literatura, estados mais populosos tenderiam a apresentar resultados mais modestos para este efeito contextual. A possível explicação para esse fato estaria na ampla estrutura partidária do PSDB no estado de São Paulo. Nesse sentido, a estratégia do PSDB de nomear um candidato de outro estado que não São Paulo, mas também populoso como Minas Gerais, onde um bom desempenho já é esperado, foi correta para maximizar o efeito de "amigos e vizinhos".

É importante ressaltar que não há uma grande desproporcionalidade no nível de informação sobre o candidato Aécio Neves no seu estado natal em relação ao resto do país, o que provocaria uma vantagem do estado natal mais modesta. Aécio Neves, por ter sido governador e atual senador por Minas Gerais, já era bem conhecido dos eleitores mineiros, mas também era um nome reconhecido nas demais regiões do país graças à sua exposição nas mídias de massa, como líder do seu partido e por conta da estrutura partidária e visibilidade nacional de seu partido.

Podemos traduzir essa situação na forma de dois processos espaciais atuando simultaneamente. Por um lado, estariam as informações sobre o candidato transmitidas 
através da mídia de massa e da campanha eleitoral "atomizando-as" de uma forma igual em todo o Brasil, mesmo que interpretadas de maneiras diferentes de lugar para lugar; e por outro lado o conhecimento prévio dos mineiros sobre o candidato.

A partir apenas do conhecimento prévio pelo eleitor, seria de se esperar uma grande vantagem do candidato Aécio Neves em Minas Gerais, considerando o seu desempenho eleitoral (Tabela 2). Nas duas vezes em que disputou o governo de Minas Gerais, em 2002 e em 2006, o candidato venceu logo no primeiro turno, chegando a receber $77 \%$ dos votos em sua reeleição.

Tabela 2: Votos obtidos por Aécio Neves, nas eleições para presidente (2014), senador (2010) e governador (2006 e 2002) no estado de Minas Gerais (\%)

\begin{tabular}{lllll}
\hline Ano & Cargo & PSDB & PT & Terceiro Colocado \\
\hline 2014 & Presidente & $39,8 \%$ & $43,5 \%$ & $14,0 \%$ \\
2010 & Senador & $39,5 \%$ & $24,0 \%$ & $26,8 \%$ \\
2006 & Governador & $77,0 \%$ & $22,0 \%$ & $0,6 \%$ \\
2002 & Governador & $57,7 \%$ & $30,72 \%$ & $6,7 \%$ \\
\hline
\end{tabular}

Fonte: TSE

Por fim, aplicamos a fórmula da vantagem do estado natal $(H)$ de forma desagregada na escala das microrregiões mineiras (Mapa 1). Analisando o mapa, vemos que a distribuição espacial da vantagem $H$ não ocorreu de forma homogênea. A vantagem de Aécio Neves concentrou-se no entorno da região central de Minas Gerais, onde se encontra a capital Belo Horizonte. $\mathrm{O}$ candidato perdeu votos principalmente nas regiões leste e norte do estado conhecidas por serem as regiões mais pobres do estado.

Já existem na literatura dos estudos eleitorais indícios de que, desde 2006 até pelo menos 2010, a população das regiões mais pobres do Brasil apoiou Lula e os candidatos do PT nas eleições presidenciais, principalmente graças a programas sociais de abrangência nacional por eles implementados, como o Bolsa Família, e os ganhos econômicos como o aumento real do salário mínimo (HUNTER e POWER 2007; SINGER, 2009; RENNÓ e CABELLO, 2010; TERRON e SOARES, 2010, entre outros). 
Mapa 1 - Vantagem do estado natal $(\mathrm{H})$ do candidato Aécio Neves no estado de Minas Gerais na escala de microrregiões.

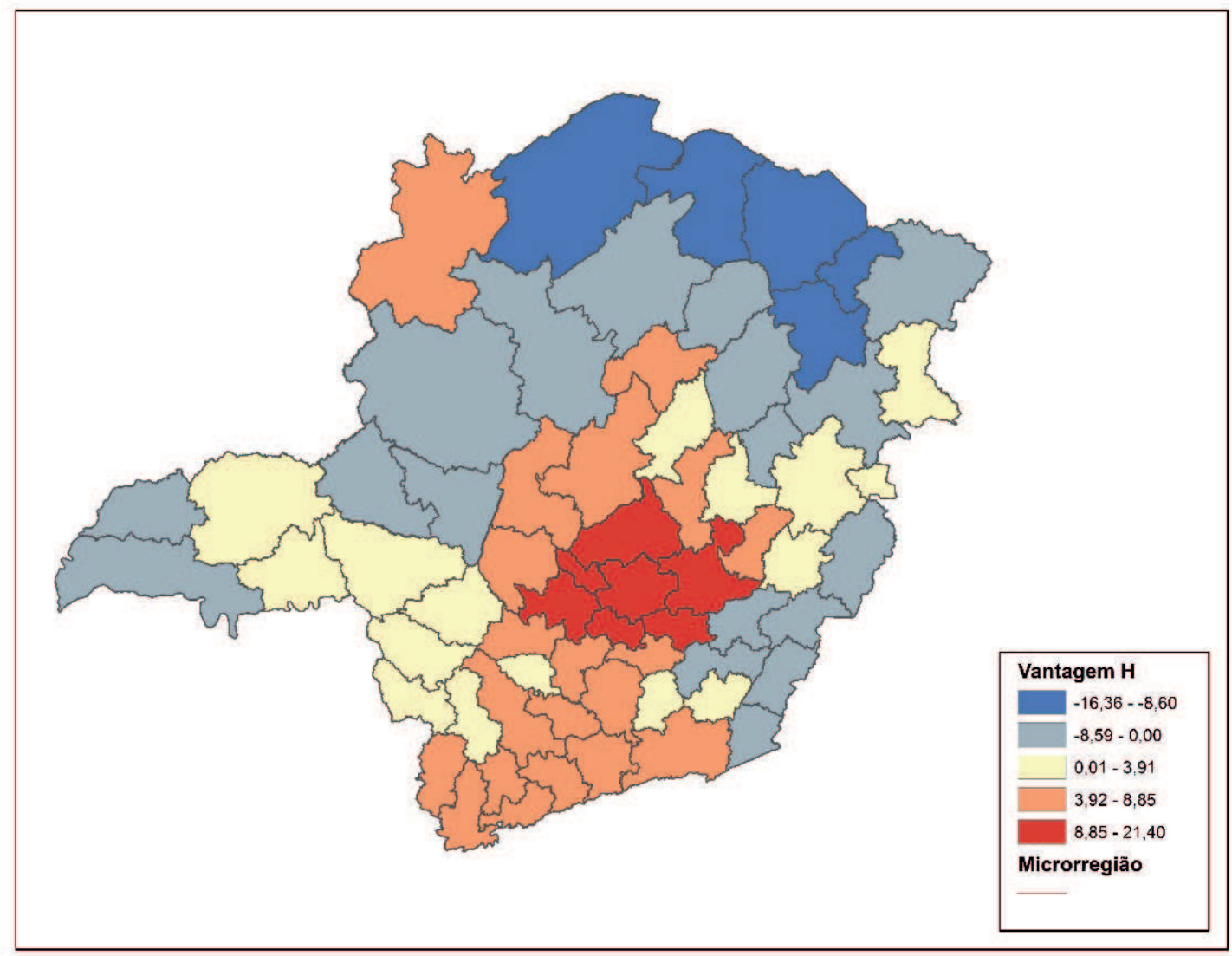

Fonte: TSE

Analisando a relação entre a vantagem $H$ do candidato Aécio Neves desagregada em microrregiões e a porcentagem de famílias que receberam bolsa família no ano de $2012^{10}$ (Gráfico 1) através de uma regressão linear simples, verificamos a existência de uma correlação negativa entre as duas variáveis. A partir desse dado é possível inferir que, nessas regiões mais pobres, os benefícios advindos dos programas sociais do PT anularam a possível vantagem do estado natal do candidato Aécio Neves, atuando como um processo concorrente.

${ }^{10}$ Fonte: IPEADATA 
Gráfico 1 - Gráfico de dispersão com curva normal representando a relação entre a vantagem do estado natal $(H)$ e a porcentagem de famílias que receberam Bolsa Família em 2012 na escala de microrregiões do estado de Minas Gerais. $N=66 R^{2}=0,444$, coeficiente $=-0,666, p$ value $=0,00$.

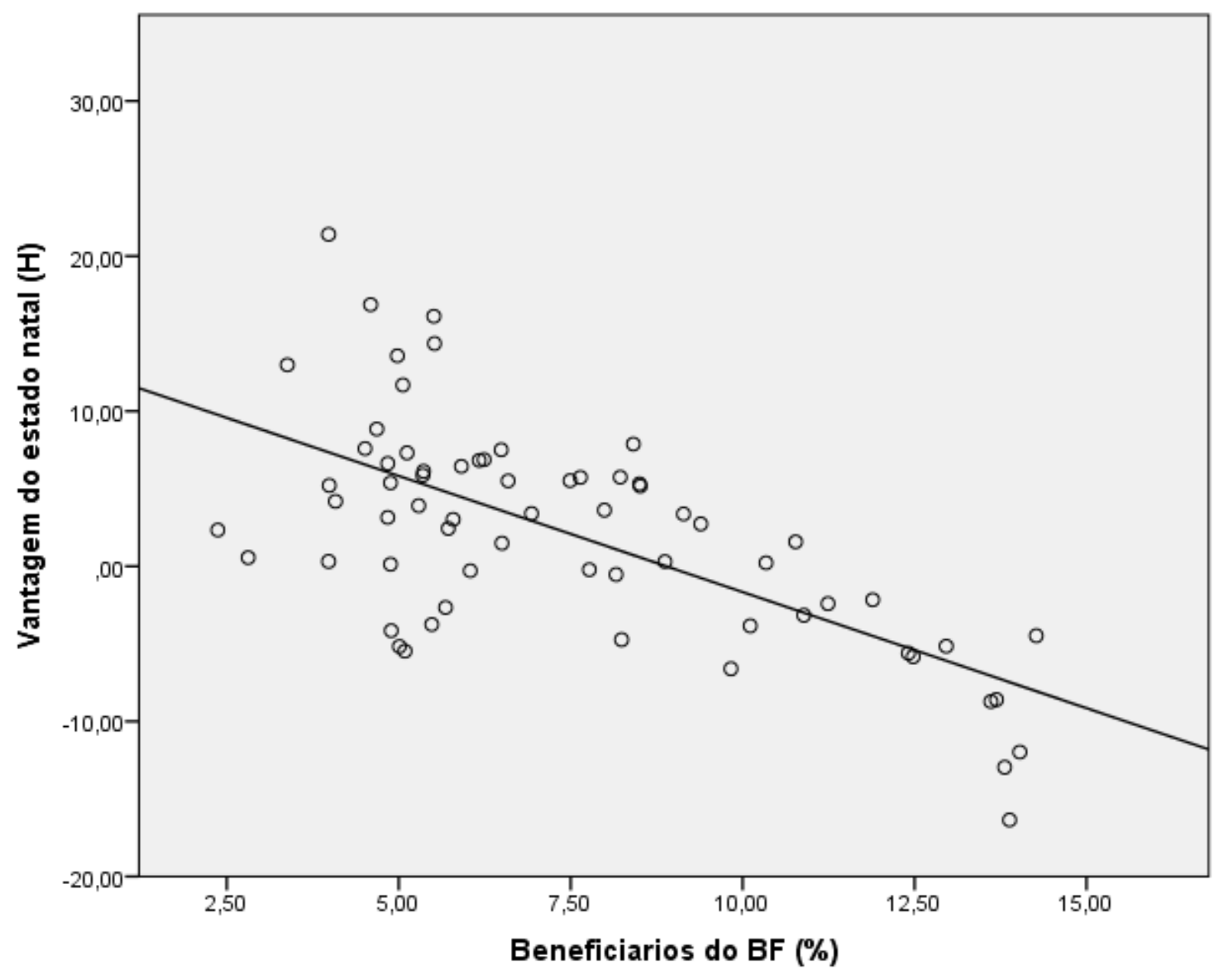

Fonte: IBGE, IPEADATA

\section{Considerações finais}

Nesse artigo apresentamos uma breve revisão da literatura americana sobre o efeito de "amigos e vizinhos", com ênfase nas eleições presidenciais, assim como sobre a própria tese contextual dentro dos estudos sobre o comportamento eleitoral, tanto na sociologia política quanto na geografia.

Vimos que o efeito de amigos e vizinhos ocorre quando a escolha do voto é determinada de acordo com a distância espacial relativa do eleitor para o local natal ou de residência do candidato. Nas eleições presidenciais americanas esse fenômeno é conhecido como a "vantagem do estado natal", e que é de amplo conhecimento dos 
estrategistas de campanha daquele país que há tempos vêm escolhendo candidatos dos estados mais populosos em busca de maximizar a vantagem desse efeito contextual.

Utilizando a fórmula que calcula a vantagem do estado natal nas eleições presidenciais introduzida por Lewis-Beck e Rice (1983), observamos que o efeito de amigos e vizinhos nas eleições presidenciais brasileiras de 1989 a 2014 é mais eficaz quanto menor a população do estado, se o candidato não é incumbente e não pertence aos dois grandes partidos PT e PSDB. Relacionamos também a importância da vantagem do estado natal $(H)$ para o candidato de acordo com o nível de estrutura partidária e de campanha que este tem à sua disposição nacionalmente.

Aplicando essa fórmula para o candidato Aécio Neves, verificou-se que o efeito de "amigos e vizinhos" no seu estado natal foi positivo para o melhor desempenho local. Ao mesmo tempo, essa vantagem não foi suficiente para derrotar sua adversária, tanto no estado como nacionalmente, devido a processos concorrentes e mais duradouros atuando no território. Nesse sentido, o desempenho de Aécio Neves no seu estado natal não justificaria sua derrota na eleição nacional, uma vez que o candidato conseguiu melhores resultados em Minas Gerais que seus partidários nas eleições anteriores. Porém, a quantidade de votos em seu estado natal afetou sua estratégia de campanha no plano nacional, que contava com uma vantagem mais expressiva em Minas Gerais.

Embora as evidências aqui apresentadas sugiram fortemente a existência de um efeito de "amigos e vizinhos" nas eleições presidenciais brasileiras, especialmente para candidatos com menor acesso a meios de comunicação de massa e partidos menos estruturados, reconhecemos que ainda é necessário um estudo mais abrangente com um maior número de casos para corroborar a nossa hipótese, principalmente para se ter um maior controle sobre as variáveis estudadas e a real influência individual de cada uma delas.

\section{Referências}

AGNEW, John. Place and Politics: The Geographical Mediation of State and Society. Boston: Allen and Unwin, 1987. 
AMES, Barry. Electoral Rules, Constituencies Pressures, and Pork Barrel: Bases of Voting in the Brazilian Congress. The Journal of Politics, 1995, vol. 57, p. 324-343.

AMES, B. A estratégia eleitoral na representação proporcional com lista aberta. Cadernos Metrópole, São Paulo, 2012, vol. 14 n. 27, p. 59-87.

AMES, B. Os entraves da democracia no Brasil. Rio de Janeiro: Fundação Getúlio Vargas, 2003

AVELINO, George et al. A Concentração Eleitoral nas Eleições Paulistas: Medidas e Aplicações. Revista dados, Rio de Janeiro, 2011, vol. 54 n.2, p. 319-347.

AVELINO, George et al. Articulações Intrapartidárias e Desempenho Eleitoral no Brasil. Revista dados, Rio de Janeiro, 2012, vol. 55 n.4, p. 987-1013.

BERELSON, Bernard, R. et al. Voting: A Study of Opinion Formation in a Presidential Election. Chicago: University of Chicago Press, 1954.

BOWLER, Shaun, et al. Local sources of information and voter choice in state elections. Microlevel foundations of the 'friends and neighbors' effect. American Politics Quarterly, 1993, vol. 21 n. 4, p.473-489.

COX, Kevin. The voting decision in a spatial context. In: BOARD, Christopher et al. Progress in Geography. Londres: Edward Arnold, 1969.

DISARRO, Brian et al. Elections: The home state efectt in presidential elections: Advances in the study of localism. Presidential Studies Quarterly, 2007, vol. 37 n. 3, p.558-566.

DOWNS, Anthony. Uma teoria econômica da democracia. São Paulo: Edusp, 1999.

HUCKFELDT, Robert; SPRAGUE, John. Networks in context: the social flow of political information. The American Political Science Review, 1987, vol. 81 n. 4, p.1197-1216.

HUCKFELT, Robert et al. Political disagreement: The survival of diverse opinions within communication networks. Cambridge: Cambridge University Press, 2004.

HUNTER, Wendy; POWER, Thimoty. Recompensando Lula. Poder Executivo, Política Social e as eleições brasileiras de 2006. In: MELO, Carlos; ALCÁNTRA, Manuel. A Democracia Brasileira. Balanço e Perspectivas para o século 21. Belo Horizonte: Editora UFMG, 2007.

JOHNSTON, Ron. The neighbourhood effect revisited: spatial science or political regionalism? Environment and Planning D: Society and Space, 1986, vol. 4, p.41 - 55. 
JOHNSTON Ron et al. Neighbourhood social capital and neighbourhood effects. Environment and Planning A, 2005, vol. 37, p.1443-1457.

JOHNSTON, Ron et al. Friends and neighbours voting revisited: The geography of support for candidates to lead the UK's Labour party. Political Geography, 2016, vol. 55, p. $1-9$.

KEY, Vladimir O. Southern politics in state and nation. New York: Knopf, 1949.

LAZARSFELD, Paul. F. The People's Choice: How the Voter Makes Up His Mind in a Presidential Campaign. Nova York: Columbia University Press, 1944.

LEWIS-BECK, Michael, S; RICE, Tom. W. Localism in presidential elections: The home state advantage. American Journal of Political Science, 1983 vol. 27 n.3, p. 548556.

MACALLISTER, Iain et al. Class Dealignment and the Neighbourhood Effect: Miller Revisited. British Journal of Political Science, 2001 vol. 31, p. 41-59.

MASSEY, Dooren. Space, Place, and Gender. Minneapolis: University of Minnesota Press, 1994.

MONTEIRO, Jorge V. Elementos da conexão eleitoral. Revista de administração pública, Rio de Janeiro, 2010, vol. 44 n.2, p.533-44.

PEREIRA, Carlos; MUELLER, Bernardo. Partidos Fracos na Arena Eleitoral e Partidos Fortes na Arena Legislativa: A Conexão Eleitoral no Brasil. Revista dados, Rio de Janeiro, 2003, vol. 46 n. 4, pp. 735 a 771.

PEREIRA, Carlos; RENNÓ, Lúcio. O que É que o Reeleito Tem? Dinâmicas PolíticoInstitucionais Locais e Nacionais nas Eleições de 1998 para a Câmara dos Deputados. Revista Dados, Rio de Janeiro, 2001, vol. 44 n.2, p. 323-362.

RENNÓ, Lúcio; CABELLO, Andrea. As bases do Lulismo: a volta do personalismo, realinhamento ideológico ou não alinhamento? Revista Brasileira de Ciências Sociais, 2010, vol. 25, p.39-60.

REYNOLDS, David. A Spatial model for analyzing voting behavior. Acta Sociologica, 1969, vol. 12, p.122-130.

RICE, Tom W; MACHT, Alisa A. Friends and neighbors voting in statewide general elections. American Journal of Political Science, 1987a, vol. 31 n.2, p. 448-452.

RICE, Tom; MACHT, Alisa A. The hometown advantage: Mobilization or conversion? Political Behavior, 1987b, vol. 9 n.3, p.257-262. 
SILVA, Glauco Peres. Uma avaliação empírica da competição eleitoral para a câmara federal no Brasil. Opinião Pública, Campinas, 2013, vol. 19 n.2, p.403-429.

SINGER, André. Raízes sociais e ideológicas do lulismo. Novos Estudos, 2009, vol. 85 n.3, p. 83-102.

TAYLOR, Peter J; JOHNSTON, Ron. The Geography of Elections. Harmondsworth: Penguin, 1979.

TERRON, Sonia; SOARES, Gláucio A. D. Dois bases eleitorais de Lula e do PT: do distanciamento ao divórcio. Opinião Pública, 2010, vol. 16 n.2, p.310-337.

WOOLSTENCROFT, Peter. Electoral Geography: Retrospect and Prospect. Politics and Geography, 1980, vol. 1 n. 4, p. 540-560.

Recebido em 11 de setembro de 2016.

Aprovado em 05 de outubro de 2016. 


\section{Anexos}

Tabela 3: Cálculo da vantagem $H$ para os candidatos que ocuparam as três primeiras colocações nas eleições presidenciais de 1989 a 2014.

\begin{tabular}{rrlllccccc}
\hline ID & \multirow{2}{*}{ Ano } & Partido & \multicolumn{1}{c}{ Candidato } & Estado Natal/Atuação & Sa & Se & Na & Ne & $\begin{array}{c}\text { VANTAGM H } \\
(\%)\end{array}$ \\
\hline 1 & 1989 & PRN & FERNANDO COLLOR & ALAGOAS & 64,4 & - & 30,4 & - & 34,0 \\
2 & 1989 & PT & LULA & SÃO PAULO & 17,5 & - & 17,2 & - & 0,3 \\
3 & 1989 & PDT & BRIZOLA & RIO DE JANEIRO & 52,1 & - & 16,5 & - & 35,6 \\
& & & & RIO GRANDE DO & & & & & \\
4 & 1989 & PDT & BRIZOLA & SUL & 62,7 & - & 16,5 & - & 46,2 \\
5 & 1994 & PSDB & FERNANDO HENRIQUE & SÃO PAULO & 55,7 & 22,7 & 54,3 & 11,5 & $-9,8$ \\
6 & 1994 & PT & LULA & SÃO PAULO & 27,0 & 17,5 & 27,0 & 17,2 & $-0,3$ \\
7 & 1994 & PRONA & ENÉAS CARNEIRO & SÃO PAULO & 8,9 & - & 7,3 & - & 1,6 \\
8 & 1998 & PSDB & FERNANDO HENRIQUE & SÃO PAULO & 59,9 & 39,2 & 53,0 & 32,9 & 0,6 \\
9 & 1998 & PT & LULA & SÃO PAULO & 28,8 & 22,3 & 31,7 & 22,1 & $-3,1$ \\
10 & 1998 & PPS & CIRO GOMES & CEARÁ & 34,2 & - & 10,9 & - & 23,3 \\
11 & 2002 & PT & LULA & SÃO PAULO & 46,1 & 24,4 & 46,4 & 25,3 & 0,6 \\
12 & 2002 & PSDB & JOSÉ SERRA & SÃO PAULO & 28,5 & 46,1 & 23,2 & 39,6 & $-1,2$ \\
13 & 2002 & PSB & GAROTINHO & RIO DE JANEIRO & 42,2 & - & 17,8 & - & 24,4 \\
14 & 2006 & PT & LULA & SÃO PAULO & 36,7 & 34,0 & 48,6 & 35,0 & $-10,9$ \\
15 & 2006 & PSDB & GERALDO ALCKMIN & SÃO PAULO & 54,2 & 48,0 & 41,6 & 53,7 & 8,3 \\
16 & 2006 & PSOL & HELOÍSA HELENA & ALAGOAS & 13,3 & - & 6,8 & - & 6,5 \\
& & & & RIO GRANDE DO & & & & &
\end{tabular}




\begin{tabular}{|c|c|c|c|c|c|c|c|c|c|}
\hline 22 & 2014 & PSB & $\begin{array}{l}\text { MARINA SILVA } \\
\text { MARINA/EDUARDO }\end{array}$ & ACRE & 42,0 & - & 21,3 & - & 20,7 \\
\hline 23 & 2014 & PSB & CAMPOS & PERNAMBUCO & 48,0 & - & 21,3 & - & 26,7 \\
\hline
\end{tabular}

Tabela 4: Vantagem eleitoral do estado natal $(H)$ obtida pelos três primeiros candidatos das eleições presidenciais de 1989 a 2014 e variáveis independentes utilizadas para o cálculo da regressão linear simples.

\begin{tabular}{|c|c|c|c|c|c|c|c|c|c|c|}
\hline ID & Ano & Partido & Candidato & Estado Natal/Atuação & VANTAGEM H (\%) & COLOCAÇÃO GERAL & POPULAÇÃO & INCUMBENTE & TEMPO & PT_PSDB \\
\hline 1 & 1989 & PRN & FERNANDO COLLOR & ALAGOAS & 34,0 & 1,0 & 1,6 & 0,0 & 1,0 & 0,0 \\
\hline 2 & 1989 & PT & LULA & SÃO PAULO & 0,3 & 2,0 & 21,7 & 0,0 & 1,0 & 1,0 \\
\hline 4 & 1989 & PDT & BRIZOLA & RIO GRANDE DO SUL & 46,2 & 3,0 & 5,5 & 0,0 & 1,0 & 0,0 \\
\hline 5 & 1994 & PSDB & FERNANDO HENRIQUE & SÃO PAULO & $-9,8$ & 1,0 & 21,7 & 1,0 & 2,0 & 1,0 \\
\hline 6 & 1994 & PT & LULA & SÃO PAULO & $-0,3$ & 2,0 & 21,7 & 0,0 & 2,0 & 1,0 \\
\hline 8 & 1998 & PSDB & FERNANDO HENRIQUE & SÃO PAULO & 0,6 & 1,0 & 21,7 & 1,0 & 3,0 & 1,0 \\
\hline 9 & 1998 & PT & LULA & SÃO PAULO & $-3,1$ & 2,0 & 21,7 & 0,0 & 3,0 & 1,0 \\
\hline 10 & 1998 & PPS & CIRO GOMES & CEARÁ & 23,3 & 3,0 & 4,4 & 0,0 & 3,0 & 0,0 \\
\hline 11 & 2002 & $\mathrm{PT}$ & LULA & SÃO PAULO & 0,6 & 1,0 & 21,7 & 0,0 & 4,0 & 1,0 \\
\hline 12 & 2002 & PSDB & JOSÉ SERRA & SÃO PAULO & $-1,2$ & 2,0 & 21,7 & 1,0 & 4,0 & 1,0 \\
\hline 13 & 2002 & PSB & GAROTINHO & RIO DE JANEIRO & 24,4 & 3,0 & 8,1 & 0,0 & 4,0 & 0,0 \\
\hline 14 & 2006 & PT & LULA & SÃO PAULO & $-10,9$ & 1,0 & 21,7 & 1,0 & 5,0 & 1,0 \\
\hline 16 & 2006 & PSOL & HELOÍSA HELENA & ALAGOAS & 6,5 & 3,0 & 1,6 & 0,0 & 5,0 & 0,0 \\
\hline 17 & 2010 & PT & DILMA ROUSSEFF & RIO GRANDE DO SUL & $-0,2$ & 1,0 & 5,5 & 1,0 & 6,0 & 1,0 \\
\hline 18 & 2010 & PSDB & JOSÉ SERRA & SÃO PAULO & $-0,2$ & 2,0 & 21,7 & 0,0 & 6,0 & 1,0 \\
\hline 19 & 2010 & PV & MARINA SILVA & ACRE & 4,1 & 3,0 & 0,4 & 0,0 & 6,0 & 0,0 \\
\hline 20 & 2014 & PT & DILMA ROUSSEFF & RIO GRANDE DO SUL & 7,3 & 1,0 & 5,5 & 1,0 & 7,0 & 1,0 \\
\hline
\end{tabular}


212014 PSDB

222014 PSB

232014 PSB

AÉCIO NEVES

MARINA SILVA

MARINA/EDUARDO CAMPOS
MINAS GERAIS

ACRE

PERNAMBUCO
7,2

20,7

26,7
2,0

3,0
10,2

0,4

4,6
0,0

0,0

7,0

7,0
1,0

0,0 0,0 